\title{
A Versatile Vacuum Ultraviolet Ion Source for Reduced Pressure Bipolar Chemical Ionization Mass Spectrometry
}

\author{
Martin Breitenlechner ${ }^{1,2}$, Gordon A. Novak ${ }^{1,2}$, J. Andrew Neuman ${ }^{1,2}$, Andrew W. Rollins ${ }^{1}$ and Patrick R. \\ Veres $^{1}$ \\ $5 \quad$ 'NOAA Chemical Science Laboratory (CSL), 325 Broadway, Boulder, Colorado 80305, USA \\ ${ }^{2}$ Cooperative Institute for Research in Environmental Sciences (CIRES), University of Colorado Boulder, Boulder, Colorado \\ 80309, USA \\ Correspondence to: Patrick (Patrick.Veres@noaa.gov)
}

\begin{abstract}
10 We present the development of a Chemical Ionization Mass Spectrometer (CIMS) ion source specifically designed for in situ measurements of trace gases in the upper troposphere and lower stratosphere. The ion source utilizes a commercially available photoionization krypton lamp, primarily emitting photons in the vacuum ultraviolet (VUV) region at wavelengths of 124 and 117 $\mathrm{nm}$ (corresponding to energies of 10 and $10.6 \mathrm{eV}$, respectively), coupled to a commercially available Vocus Proton Transfer Reaction Mass Spectrometer. The VUV ion source can produce both negative and positive reagent ions, however, here we primarily

15 focus on generating iodide anions $\left(\mathrm{I}^{-}\right)$. The instrument's drift tube (also known as ion molecule reactor) operates at pressures between 2 and $10 \mathrm{mbar}$, which facilitates ambient sampling at atmospheric pressures as low as 50 mbar. The low operating pressure reduces secondary ion chemistry that can occur in iodide CIMS. It also allows the addition of water vapor to the drift tube to exceed typical ambient humidity by more than one order of magnitude, significantly reducing ambient humidity dependence of sensitivities. An additional benefit of this ion source and drift tube is a 10 to 100 -fold reduction in nitrogen consumed during operation relative to standard $\mathrm{I}^{-}$ion sources, resulting in significantly reduced instrument weight and operational costs. In iodide mode, sensitivities of $76 \mathrm{cps} / \mathrm{ppt}$ for nitric acid, $35 \mathrm{cps} / \mathrm{ppt}$ for $\mathrm{Br}_{2}$, and $8.9 \mathrm{cps} / \mathrm{ppt}$ for $\mathrm{Cl}_{2}$ were achieved. Lastly, we demonstrate that this ion source can generate benzene $\left(\mathrm{C}_{6} \mathrm{H}_{6}{ }^{+}\right)$and ammonium $\left(\mathrm{NH}_{4}^{+}\right)$reagent ions to expand the number of detected atmospheric trace gases.
\end{abstract}

\section{Introduction}

25 Chemical ionization mass spectrometry (CIMS) has been widely used as a powerful tool to detect atmospheric compounds present at trace levels (de Gouw and Warneke, 2007; Huey, 2007). In CIMS, reagent ions undergo mostly non-dissociating ion-molecule reactions in the ion molecule reactor (IMR). The resulting product ions are detected by a mass spectrometer. Modern instruments typically utilize time-of-flight mass spectrometers (ToF-MS) due their high mass resolving power capable of separating many isobars and simultaneous detection of ions over a wide mass range. The CIMS technique allows for accurate detection of atmospheric trace gases with high sensitivity, low detection limits and fast time responses. Additionally, CIMS is a highly customizable measurement technique that allows for the detection of a wide range of analyte species through reagent ion selection, utilizing both positive and negative reagent ions.

Common negative ion chemical ionization schemes include nitrate (Eisele and Tanner, 1993), trifluoromethoxy anion $\left(\mathrm{CF}_{3} \mathrm{O}^{-}\right.$;

35 Crounse et al., 2006), acetate (Veres et al., 2008; Bertram et al., 2011) and iodide anions (Caldwell et al., 1989; Slusher et al., 2004; Lee et al., 2014). Relative to nitrate ion CIMS, which is highly selective to sulfuric acid (Jokinen et al., 2012), amines (Simon 
et al., 2016) and highly oxygenated molecules (Ehn et al., 2014), $\mathrm{CF}_{3} \mathrm{O}^{-}$, acetate or iodide are less selective and therefore are typically operated at reduced pressures to avoid depletion of primary ions and secondary ion chemistry. Iodide anions in particular have been used for the detection of both organic and inorganic acids (Roberts et al., 2010), including reactive nitrogen species

$40\left(\mathrm{HNO}_{3}, \mathrm{HONO}, \mathrm{HO}_{2} \mathrm{NO}_{2}\right.$, peroxy acetyl nitrates, $\left.\mathrm{N}_{2} \mathrm{O}_{5}\right)$ and halogens $\left(\mathrm{ClNO}_{2}, \mathrm{HCl}, \mathrm{BrO}, \mathrm{HOBr}, \mathrm{HOCl}, \mathrm{Cl}_{2}, \mathrm{Br}_{2}\right)(\mathrm{Neuman}$ et al., 2010; Lee et al., 2014; Liao et al., 2014; Lee et al., 2018; Slusher et al., 2004).

Positive ion CIMS ionization schemes include Proton-Transfer-Reaction mass spectrometry (PTR-MS, Hansel et al., 1995), which detects a wide range of organic compounds utilizing proton transfer reactions from hydronium ions, or more selective ionization schemes such as $\mathrm{O}_{2}{ }^{+}$(Norman et al., 2007), $\mathrm{NO}^{+}$(Karl et al., 2012), ammonium reagent ions $\left(\mathrm{NH}_{4}{ }^{+}\right.$, Zaytsev et al., 2018, Müller et al., 2020) and benzene ions (Leibrock and Huey, 2000; Kim et al., 2016; Lavi et al., 2018).

The primary goal of this work is to leverage the flexibility of the CIMS technique to develop an instrument capable of detecting a wide range of molecules in the upper troposphere and lower stratosphere (UT/LS) onboard a research aircraft which can operate

50 up to $20 \mathrm{~km}$ altitude. The work presented here focuses on detailing the design and performance of a new ion source and instrument configured to meet several key challenges related to deployment of CIMS in the UT/LS: 1) flexibility in target analyte species, 2) sampling from pressure as low as 50 mbar, and 3) secondary ion chemistry anticipated due to the sample matrix. The specific challenges related to engineering a research grade instrument for operation in a low-pressure environment will be addressed in a future manuscript. Here we provide details on the design and performance of the ToF-MS instrument and our custom designed

55 VUV ion source. Our results primarily focus on iodide ion reagent ions that are chosen to provide UT/LS observations of reactive nitrogen species and halogens. We present signal intensities, cluster distributions, sensitivities, limits of detection and an assessment of potential secondary ion chemistry. Additionally, we illustrate the versatility of the VUV ion source by highlighting its ability to generate benzene ions $\left(\mathrm{C}_{6} \mathrm{H}_{6}{ }^{+}\right)$and ammonium ions $\left(\mathrm{NH}_{4}^{+}\right)$.

\section{Materials and methods}

60 The CIMS instrumentation used in this work was chosen to address the coupled issues of reduced pressure operation and interferences from secondary ion chemistry. Aircraft sampling inlets are commonly pressure controlled to maintain a pressure well below the minimum ambient pressure to be sampled (Veres et al. 2020) so that instrument operating conditions are insensitive to changes in aircraft altitude. High altitude aircraft that measure in the UT/LS can reach ambient pressures as low as 50 mbar. This pressure regime presents a challenge to standard iodide CIMS instrumentation that typically operates with an IMR pressure between 30 and 100 mbar. These pressures are necessary in order to maximize sensitivities by optimizing the number of collisions between reagent ions and reactants. However, pressure dependent secondary ion reactions can make interpretation of the observed mass spectra difficult, potentially leading to the misidentification of product ion species. For example, ozone levels exceed $1000 \mathrm{ppb}$ in the LS, which can promote secondary ion chemistry originating from reagent ions being transformed by ozone in the IMR (Dörich et al., 2021; Zhang and Zhang, 2021; Section 3.3). Unfortunately, limiting secondary reactions requires a reduction in operating

70 pressure, which will have an adverse impact on instrument sensitivities and detection limits in a standard CIMS instrument.

The pressure regime and bipolar electronics of the Vocus PTR-ToF instrument (Model S, Tofwerk AG, Thun, Switzerland) are particularly well-suited for this work. In the Vocus, the IMR is a drift tube that operates at pressures typically between 2 and 4 mbar, ideal for both limiting secondary ion reactions as well as allowing for adequate pressure control at high altitude. To 
75 compensate for the lower collision frequencies at these pressures, an ion focusing quadrupole ion guide surrounding the drift tube enhances the transmission efficiency from the drift tube into the mass spectrometer. While the commercially available Vocus instrument is designed to operate in positive ion mode utilizing $\mathrm{H}_{3} \mathrm{O}^{+}$primary ions, bipolar electronics allow for implementation of negative ion modes such as iodide anion CIMS. This feature allows for a large range of target analyte species with minimal instrument modifications. Therefore, the Vocus was chosen as a platform to develop a CIMS that is highly sensitive and operates at low pressures - which is both suitable for high altitude deployment and in environments of high ozone levels, where secondary ion chemistry is of concern.

\subsection{Vocus PTR-ToF}

The Vocus is primarily designed to operate as a PTR-CIMS using hydronium ions $\left(\mathrm{H}_{3} \mathrm{O}^{+}\right)$as reagent ions coupled to a drift tube as an IMR (Krechmer et al., 2018) to reduce clustering of hydronium ions with omnipresent water vapor molecules in the sample gas. Proton transfer reactions take place in a resistive glass drift tube which is surrounded by a quadrupole ion guide. The glass drift tube is $100 \mathrm{~mm}$ long and provides an axial electric field which can be set between zero and $80 \mathrm{~V} / \mathrm{cm}$. The electric field effectively supresses cluster formation of hydronium ions with water molecules at typical operating conditions of $60 \mathrm{~V} / \mathrm{cm}$ at 2 mbar (The reduced electric field, E/N, expressed in units of Townsend (Td) is calculated as follows: $\frac{E}{N}=1.38 \cdot \frac{T[K]}{p[P a]} \cdot E\left[\frac{\mathrm{V}}{\mathrm{cm}}\right] ; 60$ $\mathrm{V} / \mathrm{cm}$ at 2 mbar at $20{ }^{\circ} \mathrm{C}$ equals $121 \mathrm{Td}$ ). The surrounding quadrupole focuses ions in the center of the device, reducing ion losses at the exit of the drift tube and effectively increasing ion transmission and sensitivity approx. 10- to 100-fold compared to classical PTR-MS drift tubes (Krechmer et al, 2018). The instrument is equipped with a positive DC glow discharge, producing hydronium primary cations $\left(\mathrm{H}_{3} \mathrm{O}^{+}\right)$, using pure water vapor as a source gas (Chemical ionization gas, CI gas). Contrary to many earlier PTRMS instruments (Hansel et a., 1995, de Gouw et al., 2003), water vapor is not removed from the system before mixing with the analyte gas in the drift tube (Krechmer et al., 2018). The resulting elevated water vapor concentration reduces the dependence of sensitivity on ambient humidity (Krechmer et al., 2018) compared to previous PTR-MS instruments (Warneke et al., 2000). While the Vocus PTR is typically used in positive ion mode, it can be switched to negative polarity. However, the glow discharge ion source cannot efficiently produce negative ions, so a different ion source is required to operate in negative mode. The Vocus model

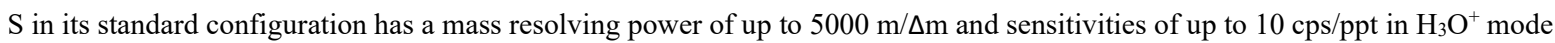
(Tofwerk AG Vocus product website, 2021).

\section{$100 \quad 2.2$ VUV lamps}

In this work, the glow discharge ion source used in the Vocus PTR-TOF was replaced with two vacuum ultraviolet lamps (Restek photoionization lamp, model 108-BTEX, Restek Corporation, PA, USA). The lamps are powered by a 3W DC Voltage supply, initially providing $1500 \mathrm{VDC}$ to ignite the lamp. The supply is current limited to $1 \mathrm{~mA}$, resulting in a continuous operating voltage of approx. $350 \mathrm{~V}$. The lamps primarily emit photons at wavelengths of 124 and $117 \mathrm{~nm}$, corresponding to photon energies of 10 and $10.6 \mathrm{eV}$, respectively. Ji et al (2020) pioneered the use of VUV lamps to produce iodide ions using a mixture of nitrogen and methyl iodide as a CI gas. This approach is versatile since the emitted photons ionize a multitude of molecules, provided their ionization energy is below $10.6 \mathrm{eV}$. Examples include ammonia $\left(\mathrm{NH}_{3}\right)$, benzene $\left(\mathrm{C}_{6} \mathrm{H}_{6}\right)$, toluene $\left(\mathrm{C}_{7} \mathrm{H}_{8}\right)$ and xylene $\left(\mathrm{C}_{8} \mathrm{H}_{10}\right)$ as well as some small alkenes such as propene $\left(\mathrm{C}_{3} \mathrm{H}_{6}\right)$.

These photoionization lamps produce reagent ions similarly to glow discharge ion sources, but differences exist: In a glow discharge, a "self-cleaning" mechanism converts all fragments that arise from electron impact ionization of components present in the CI gas into a suitable primary species. One well-known system where this process is effective is the generation of $\mathrm{H}_{3} \mathrm{O}^{+}$ions in a glow discharge (with pure water vapor as a CI gas) in a PTR-MS instrument: All possible fragments of electron impact 
ionization of $\mathrm{H}_{2} \mathrm{O}\left(\mathrm{H}^{+}, \mathrm{H}_{2}{ }^{+}, \mathrm{OH}^{+}, \mathrm{O}^{+}\right)$as well as $\mathrm{H}_{2} \mathrm{O}^{+}$undergo subsequent reactions with water molecules to form $\mathrm{H}_{3} \mathrm{O}^{+}$primary ions (Hansel et al., 1995). One advantage of the VUV ion source described here is the absence of fragment ion species in the ion

115 source: eg. in the case of benzene, the fragment having the lowest appearance energy (AE) is $\mathrm{C}_{6} \mathrm{H}_{5}{ }^{+}$with an $\mathrm{AE}$ of $12.90 \mathrm{eV}$. This energy is well above the most energetic photons emitted by the lamp $(10.6 \mathrm{eV})$ and therefore no fragments are expected anywhere in the source. This "soft" primary ionization allows for mixing of source gases without the complication of having to take into account secondary reactions of fragments with any member of the CI gas. Another advantage of the VUV source and its "soft" ionization process is the absence of fast ions or electrons and subsequent sputtering processes in the ion source region, resulting in increased longevity of the ion source region without the need of cleaning.

\subsection{Ion source design and coupling to the Vocus drift tube}

To sample trace gases in the atmosphere, the pressure must be reduced from ambient pressure to a few mbar in the drift tube, and this is accomplished using several stages of pumping. The sample gas inlet consists of a PFA tube (ID $7.5 \mathrm{~mm}$ ). The inlet is connected to a pump through a custom-made butterfly valve with minimal pressure drop to allow for a sampling flow of up to 10 slpm (at sea level). A pressure control system comprising another custom-built butterfly valve keeps the pressure in the region between the two critical orifices at 40 mbar, which is sensed through a separate port. The low impedance pumping port and the butterfly valve of this pressure control system allow for a wide dynamic range of ambient pressures, ranging from ground-level to a simulated altitude of $20 \mathrm{~km}$ (50 mbar). As described in section 3.1, in iodide mode, the drift voltage is set to zero in order to maximize sensitivity. As a result, reaction times of ions with molecules present in the sample (and, consequently, sensitivities) solely depend on the gas flow through the drift tube. Therefore, a second stage pressure control system, regulating flow through the drift tube, compensates for potential changes of pumping speeds with aircraft altitude and assures that the reaction time of ions (affecting sensitivities) does not change in the absence of an electric field.

Figure 1 shows the coupling of the inlet to the ion source comprised of the VUV lamp and the Vocus drift tube. In this figure, one VUV lamp is shown for simplicity, however, the current design utilizes a second VUV lamp mounted at $180^{\circ}$. The sampled air enters the drift tube through a $12 \mathrm{~mm}$ long PEEK capillary (ID $0.5 \mathrm{~mm}$, with a typical flow rate of approx. $100 \mathrm{sccm}$ ), which is surrounded by a stainless steel sleeve, preventing exposure of the sample gas to photons emitted by the VUV lamps. The CI gas is introduced with a typical flow rate of approx. $20 \mathrm{sccm}$ shared between the lamps. The lower operating pressure of the Vocus allows for the reduction of the total ion source flow to $20 \mathrm{sccm}$, while previous I- CIMS operate at elevated IMR pressures and typically consume 0.5 to $2 \mathrm{slpm}$ of a methyl iodide/ $\mathrm{N}_{2}$ mixture (Veres 2020, Lee et al. 2014). A separate inlet port for humidification supplies pure water vapor from the headspace of a liquid water reservoir to the sample gas, typically between 10 and $20 \mathrm{sccm}$. This results in humidity levels in the drift tube that exceed typical ambient water vapor concentrations by at least an order of magnitude. As shown in Figure 2, this has the advantage of establishing a reagent ion cluster distribution (and subsequently sensitivities) that is largely independent of the sample humidity. 


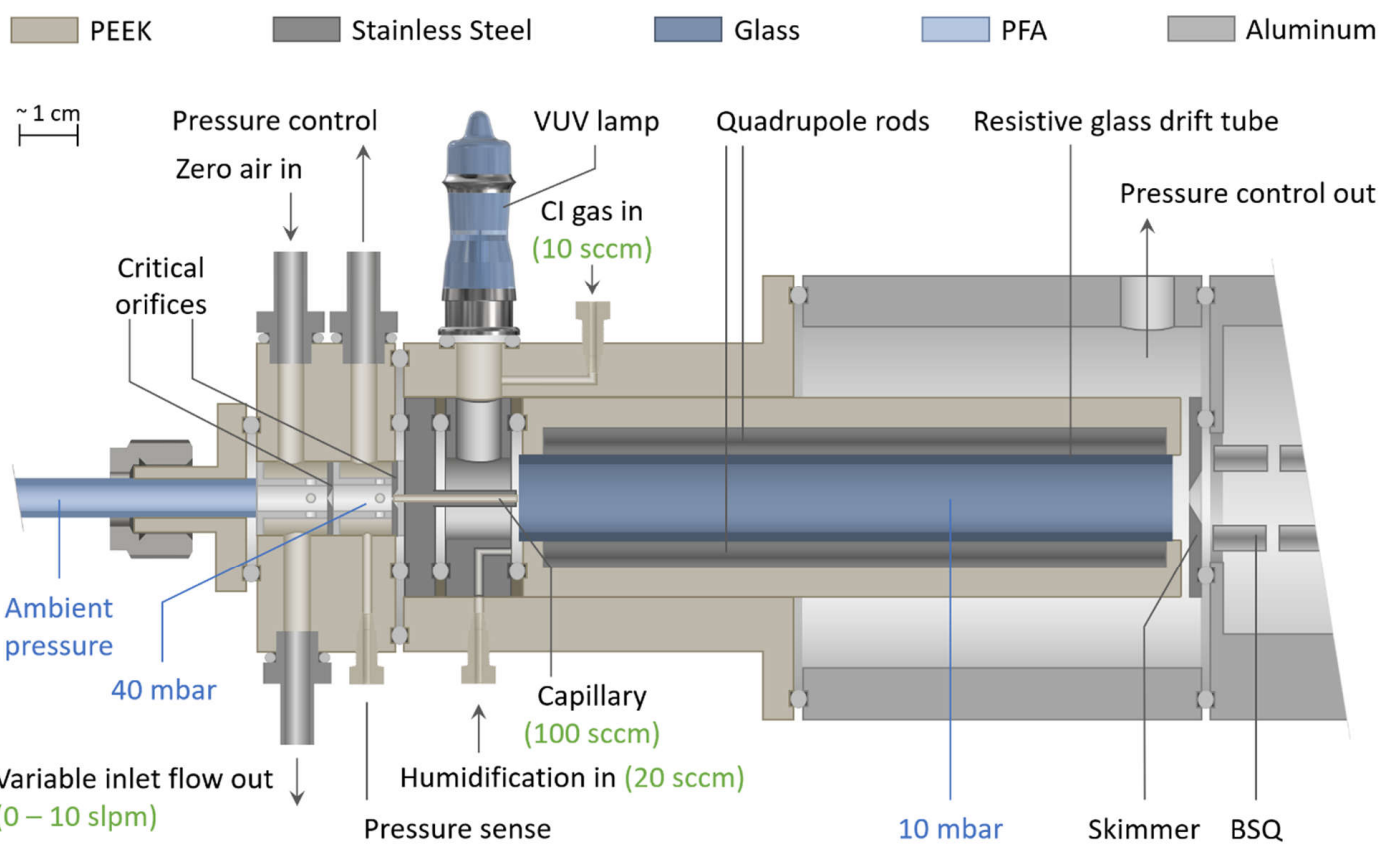

Figure 1: The VUV ion source coupled to the Vocus PTR-ToF-MS. Note that only one VUV lamp is shown. Green numbers represent approximate typical flow rates.

Details on the generation of reagent ions will be described in the following sections. Briefly, the CI gases used were (1) a custommade gas cylinder containing methyl iodide with a volume mixing ratio of $1000 \mathrm{ppm}$ in nitrogen with a typical flow rate of typically $20 \mathrm{sccm}$ for generating iodide ions; (2) a liquid reservoir of benzene at room temperature and ambient pressure which is overflown by 10 to $20 \mathrm{sccm}$ UHP nitrogen for generating benzene reagent ions; and (3) a similar setup with a $0.1 \%$ ammonium hydroxide solution reservoir for generating ammonium $\left(\mathrm{NH}_{4}^{+}\right)$reagent ions.

\section{Results and discussion}

\subsection{Iodide ion CIMS}

Iodide ions are commonly used for trace gas detection in CIMS instruments, and the measurement sensitivity and selectivity are dictated by the conditions in the IMR/drift tube. Iodide adduct formation from $\mathrm{I}^{-}$reagent ions can generally be described as follows: $I^{-}+R \rightarrow\left[I^{-} \cdot R\right]^{*} \stackrel{M}{\longrightarrow} I^{-} \cdot R$,

where $\mathrm{R}$ is the sample molecule and the asterisk denotes a short-lived excited state, which can be stabilized via collisions with a third body M. (Caldwell et al, 1989). The efficiency of collisional stabilization is pressure dependent and is generally less effective at the lower operating pressures used in this work.

Iodide readily clusters with water, and the resulting cluster ions also serve as reagent ions for many species of interest. Therefore, especially at low pressures, ligand switching reactions with iodide-water clusters leading to the same $\mathrm{I}^{\bullet} \cdot \mathrm{R}$ adduct ion are important: $I^{-} \cdot \mathrm{H}_{2} \mathrm{O}+\mathrm{R} \rightarrow \mathrm{I}^{-} \cdot \mathrm{R}+\mathrm{H}_{2} \mathrm{O}$.

165 These reactions are exothermic if the binding energy (BE) of $\mathrm{I}^{-} \bullet \mathrm{R}$ exceed the $\mathrm{BE}$ of $\mathrm{I}^{-} \bullet \mathrm{H}_{2} \mathrm{O}(43 \mathrm{~kJ} / \mathrm{mol}$, NIST Chemistry Webbook, 2021). The added humidification port (see Figure 1) provides the possibility to add pure water vapor, promoting the formation of 
$\mathrm{I}^{\bullet} \cdot\left(\mathrm{H}_{2} \mathrm{O}\right)_{\mathrm{n}}$ and adduct formations from reaction 2. Figure 2 shows the effect of adding water to the drift tube on the reagent ion cluster distribution. The distributions were calculated based on measured equilibrium constants (Enthalpy and Entropy changes) for the iodide-water system (Hiraoka et al., 1988, de Gouw et al., 2003). As shown in panel b), figure 2, ambient humidity has no significant effect on the cluster distribution when water is directly added to the drift tube. In figure 2c), we show the calculated residence time of the $\mathrm{I}^{-} \cdot \mathrm{H}_{2} \mathrm{O}$ cluster in the drift tube based on a drift velocity resulting from a reduced ion mobility of $1.6 \mathrm{~cm} / \mathrm{Vs}$ (Kilpatrick, 1971). In the absence of an electric field $(\mathrm{E} / \mathrm{N}=0 \mathrm{Td})$, the reaction time is estimated based on the gas exchange rate; at elevated reduced electric fields, the reaction time decreases due to increasing ion drift velocity. The reaction time of ions with the sample gas is directly proportional to the sensitivity (when normalized to primary ion intensity - or, in absolute terms, when

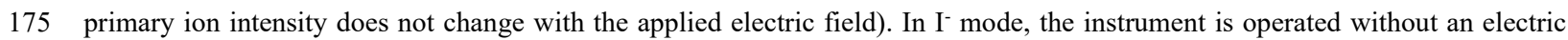
field applied over the length of the drift tube, to maximize sensitivity as discussed earlier. Figure 3 shows a mass spectrum obtained during a calibration experiment (formic acid and nitric acid added to zero-air). During this experiment, the drift tube pressure was 9 mbar, with $18 \mathrm{sccm}$ of water vapor added.

Table 1 shows the observed reagent ion intensities for $\mathrm{I}^{-}(\mathrm{m} / \mathrm{z}=126.9050 \mathrm{Th}), \mathrm{I}^{\bullet} \bullet \mathrm{H}_{2} \mathrm{O}(\mathrm{m} / \mathrm{z}=144.9156 \mathrm{Th})$ and $\mathrm{I}^{\bullet} \bullet\left(\mathrm{H}_{2} \mathrm{O}\right)_{2},(\mathrm{~m} / \mathrm{z}=$

$180162.9262 \mathrm{Th}$ ) and their respective distribution. Note that observed cluster distributions are expected to differ from the distributions in the IMR because the mass spectrum is affected by voltages in the ion transfer region between the drift tube and the mass analyser. These voltages were optimized for maximum ion intensities of product ions (which have stronger binding energies than the $\mathrm{I}^{-} \cdot \mathrm{H}_{2} \mathrm{O}$ cluster) rather than being optimized for minimum collision activation of ions and avoiding de-clustering in this region. 

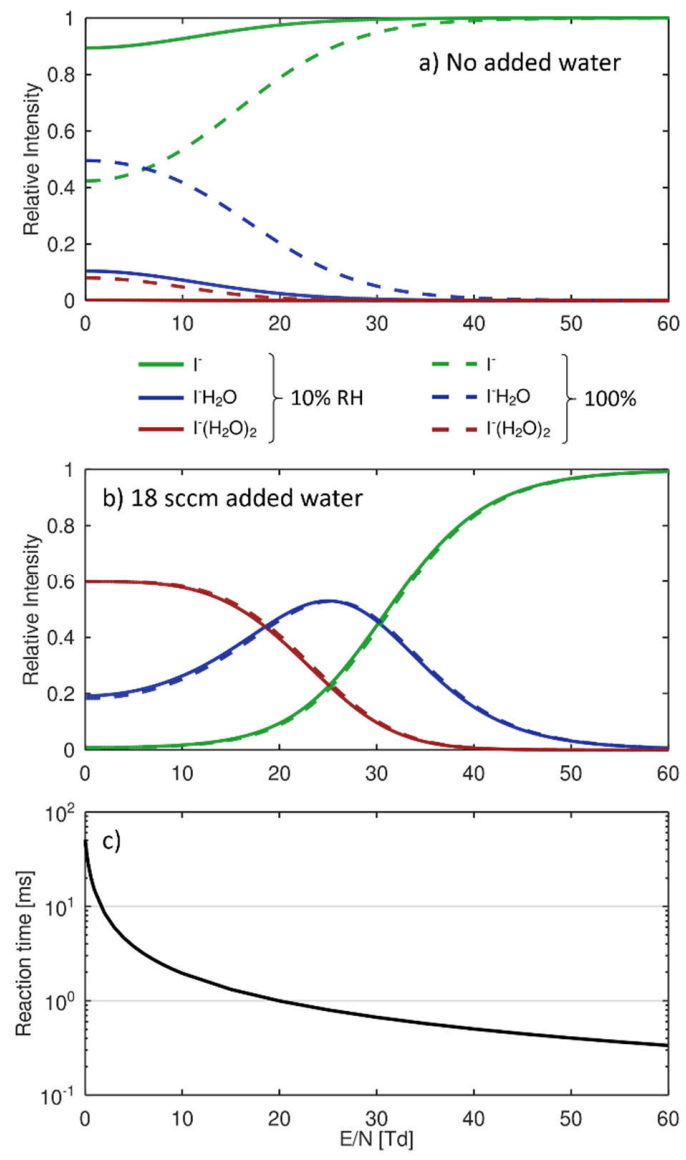

Figure 2: Calculated cluster distributions based on enthalpy and entropy changes of association and dissociation reactions of the $\mathrm{I}$-water system. Solid lines show data for $100 \%$ relative humidity $(\mathrm{RH})$ of the sample gas at $25{ }^{\circ} \mathrm{C}$; dotted lines represent $10 \% \mathrm{RH}$ at $25{ }^{\circ} \mathrm{C}$. Panel a: no added water to the drift tube; Panel b: $18 \mathrm{sccm}$ of water vapor added to the drift tube (approx. 1 mbar partial pressure); Panel c) Reaction time of $\mathrm{I}^{-} \cdot \mathrm{H}_{2} \mathrm{O}$ as a function of reduced electric field $(\mathrm{E} / \mathrm{N})$.

Table 1: Reagent ion intensities in iodide mode

Ion intensities

Ion formula $\mathrm{m} / \mathrm{z}[\mathrm{Th}] \quad \mathrm{Cps}\left[10^{6} \mathrm{~Hz}\right] \quad$ percent

\begin{tabular}{lrrr}
\hline $\mathrm{I}^{-}$ & 126.905 & 7.0 & $63 \%$ \\
$\mathrm{I}^{-} \cdot \mathrm{H}_{2} \mathrm{O}$ & 144.9156 & 3.8 & $34 \%$ \\
$\mathrm{I}^{-} \cdot\left(\mathrm{H}_{2} \mathrm{O}\right)_{2}$ & 162.9262 & 0.37 & $3 \%$ \\
\hline total & & 11.2 & $100 \%$
\end{tabular}




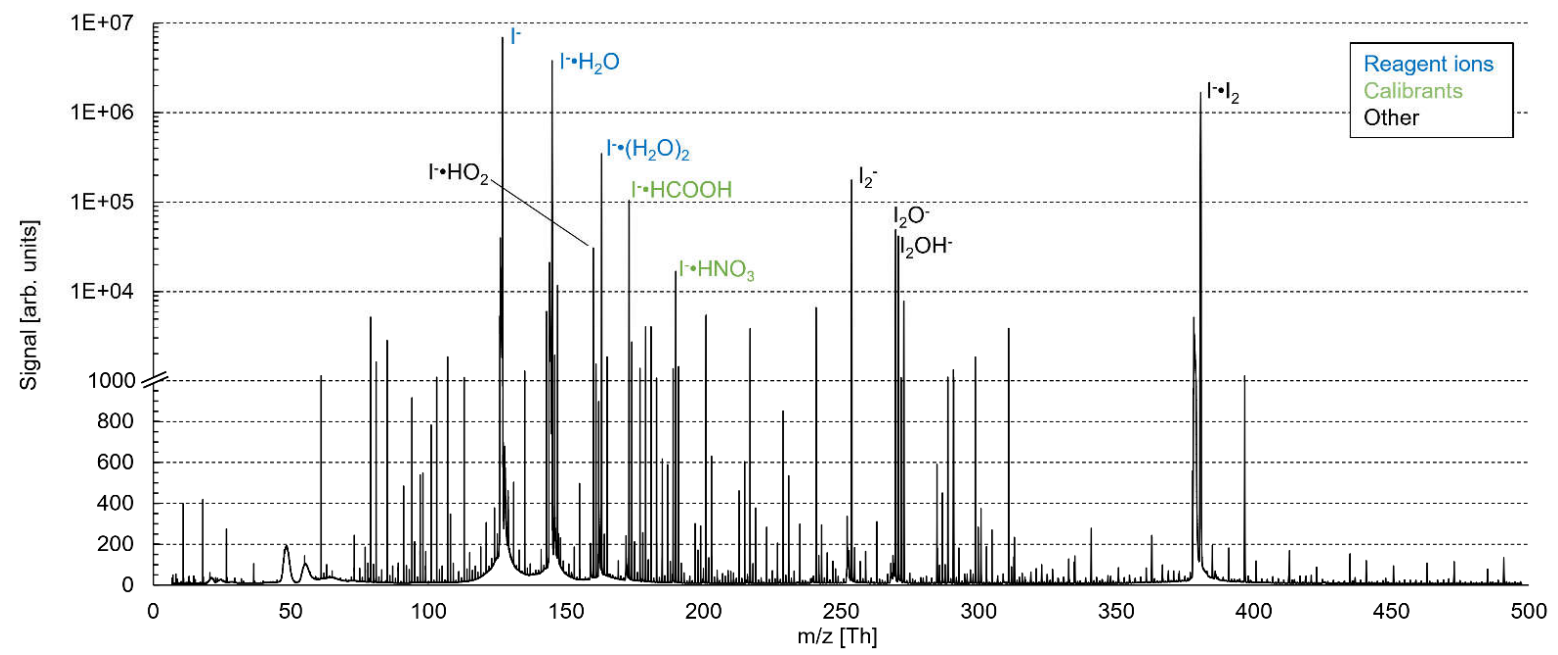

Figure 3: Mass spectrum in iodide mode. Operating conditions: drift tube pressure: 9 mbar; $\mathrm{H}_{2} \mathrm{O}$ addition: 20 scem; calibrants: 14 ppb formic acid $(\mathrm{HCOOH}), 18 \mathrm{ppb}$ nitric acid $\left(\mathrm{HNO}_{3}\right)$.

\subsection{Sensitivities and limits of detection}

215 Instrument capabilities are assessed by admitting calibration standards of inorganic acids, organic acids, and halogens into the inlet. All analyses are performed using high resolution peak fits, and the resolution was typically $4500 \mathrm{~m} / \Delta \mathrm{m}$. Sensitivities of formic acid $\left(\mathrm{I}^{-} \cdot \mathrm{HCOOH}, \mathrm{m} / \mathrm{z}=172.9105 \mathrm{Th}\right)$, nitric acid $\left(\mathrm{I}^{-} \cdot \mathrm{HNO}_{3}, \mathrm{~m} / \mathrm{z}=189.9007 \mathrm{Th}\right)$, bromine $\left(\mathrm{I}^{-} \cdot \mathrm{Br}_{2}, \mathrm{~m} / \mathrm{z}=284.7417 \mathrm{Th}\right)$ and chlorine $\left(\mathrm{I}^{-} \cdot \mathrm{Cl}_{2}, \mathrm{~m} / \mathrm{z}=196.8427 \mathrm{Th}\right)$ were obtained using permeation tubes, dynamically diluted with zero air. Nitryl chloride $\left(\mathrm{I}^{-}\right.$ $\cdot \mathrm{ClNO}_{2}, \mathrm{~m} / \mathrm{z}=207.8668 \mathrm{Th}$ ) was generated in a heterogenous reaction of $\mathrm{Cl}_{2}$ and $\mathrm{NO}_{2}$ as described in Thaler et al., 2011; The reaction was monitored by measuring $\mathrm{NO}_{2}$ (Ryerson et al., 2000). As shown in table 2, sensitivities range from 9 to $76 \mathrm{cps} / \mathrm{ppt}$ for these species. Limits of detection range from sub-ppt levels for $1 \mathrm{~s}$ measurements for bromine and chlorine to more than $50 \mathrm{ppt}$ for formic acid, which is limited by a high background signal in the current setup. The sensitivities obtained with this instrument are similar to iodide CIMS instruments operating at much higher pressures and longer reaction times. Ji et al. (2020), operating the IMR between 26 and 53 mbar, report sensitivities in the range of 80 to $150 \mathrm{cps} / \mathrm{ppt}$ for formic acid, chlorine and nitryl chloride, with limits of detections ranging from $0.1 \mathrm{ppt}$ to $0.6 \mathrm{ppt}$ for these species ( 1 minute integration time). Veres et al. (2020) operate their instrument at an IMR pressure of approx. $40 \mathrm{mbar}$, obtaining sensitivities on the order of $15 \mathrm{cps} / \mathrm{ppt}$ for the most sensitive compounds such as $\mathrm{Cl}_{2}, \mathrm{ClNO}_{2}$ and $\mathrm{N}_{2} \mathrm{O}_{5}$.

Figure 4 shows the humidity dependence of sensitivities for formic acid $(\mathrm{HCOOH})$ and Bromine $\left(\mathrm{Br}_{2}\right)$, normalized to the driest conditions studied $\left(\mathrm{RH}=30 \%\right.$ at an ambient temperature of $\left.22{ }^{\circ} \mathrm{C}\right)$, while $18 \mathrm{sccm}$ of water vapor was directly added to the drift tube. The change in sensitivities for both formic acid and bromine is less than $10 \%$ between $30 \%$ and $85 \%$ RH at room temperature. For comparison: Lee et al. (2014) reported that sensitivities increased by a factor of 30 for $\mathrm{Br}_{2}$ and $\mathrm{Cl}_{2}$, by a factor of 3 for $\mathrm{HNO}_{3}$ and a decrease of $20 \%$ to $80 \%$ for OVOCs $\left(\mathrm{C}_{10} \mathrm{H}_{12-18} \mathrm{O}_{2-9}\right)$ compared to dry conditions when adding 0.8 mbar of water vapor to the IMR (corresponding to $38 \% \mathrm{RH}$ at $20^{\circ} \mathrm{C}$ ). 
235 Table 2: Sensitivities and detection limits (for a sample interval of 10s, 3 standard deviations) for formic acid, nitric acid, bromine, chlorine and chlorine nitrite in iodide mode.

\begin{tabular}{l|l|l|r|r|r} 
Species & $\begin{array}{l}\text { Chemical } \\
\text { formula }\end{array}$ & $\begin{array}{l}\text { Sensitivity } \\
\text { (cps/ppt) }\end{array}$ & $\begin{array}{l}\text { Background } \\
\text { (cps) }\end{array}$ & Background & $\begin{array}{l}\text { Limit of detection } \\
10 \mathrm{~s}, 3 \sigma,(\mathrm{ppt})\end{array}$ \\
\hline Formic acid & $\mathrm{HCOOH}$ & 23 & $7.9 \cdot 10^{5}$ & $34 \mathrm{ppb}$ & 51 \\
Nitric acid & $\mathrm{HNO}_{3}$ & 76 & $5.9 \cdot 10^{4}$ & $780 \mathrm{ppt}$ & 4.3 \\
Bromine & $\mathrm{Br}_{2}$ & 35 & 220 & $6 \mathrm{ppt}$ & 0.6 \\
Chlorine & $\mathrm{Cl}_{2}$ & 8.9 & 18 & $2 \mathrm{ppt}$ & 0.7 \\
nitryl chloride & $\mathrm{ClNO}_{2}$ & 9 & 72 & $8 \mathrm{ppt}$ & 1.3
\end{tabular}

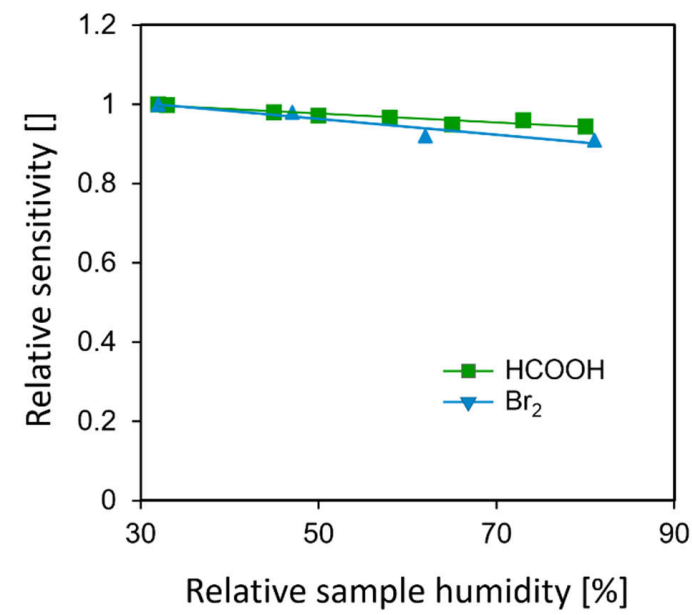

Figure 4: Relative sensitivities of formic acid $(\mathrm{HCOOH})$ and bromine $\left(\mathrm{Br}_{2}\right)$ as a function of sample relative humidity (RH; $\mathrm{T}_{\text {ambient }}=\mathbf{2 2}^{\circ} \mathrm{C}$, added $\mathrm{H}_{2} \mathrm{O}$ flow: $18 \mathrm{sccm}$ ). Sensitivities are normalized to the driest conditions $(\mathrm{RH}=\mathbf{3 0} \%)$.

\subsection{Secondary ion chemistry}

The reaction of $\mathrm{I}^{-}$reagent ions with $\mathrm{O}_{3}$ has the potential to drive secondary ion chemistry that produces interfering ions from $\mathrm{IO}^{-}$

250 and $\mathrm{IO}_{3}^{-}$(Dörich et al., 2021; Zhang and Zhang, 2021). In the typical $\mathrm{I}^{-}$ionization mode, $\mathrm{I}^{-}$forms a stable adduct with the analyte (reaction 1). If ozone levels are sufficiently high, a fraction of $\mathrm{I}^{-}$reagent ions react with $\mathrm{O}_{3}$ resulting in the production of both $\mathrm{IO}^{-}$ and $\mathrm{IO}_{3}^{-}$(reactions 3 and 4).

$$
\begin{aligned}
& I^{-}+\mathrm{O}_{3}+M \rightarrow \mathrm{IO}_{3}^{-}+M \\
& \mathrm{IO}_{3}^{-}+\mathrm{M} \rightarrow \mathrm{IO}^{-}+\mathrm{O}_{2}+\mathrm{M}
\end{aligned}
$$

255 Secondary chemistry from $\mathrm{IO}^{-}$and $\mathrm{IO}_{3}{ }^{-}$can form stable adducts with atmospheric species A, resulting in product ions that don't faithfully represent atmospheric composition:

$$
\begin{aligned}
& I O^{-}+A \rightarrow I O^{-} \cdot A \\
& I O_{3}^{-}+A \rightarrow I O^{-} \cdot A+O_{2}
\end{aligned}
$$


One example of an unwanted secondary ion chemistry effect described here affects the detection of $\mathrm{HNO}_{3}$. $\mathrm{Both}_{\mathrm{IO}_{3}}^{-}$and $\mathrm{IO}^{-}$form

$$
\begin{aligned}
& \mathrm{IO}^{-}+\mathrm{HNO}_{3} \rightarrow \mathrm{IO}^{-} \cdot \mathrm{HNO}_{3} \\
& \mathrm{IO}_{3}^{-}+\mathrm{HNO}_{3} \rightarrow \mathrm{IO}^{-} \cdot \mathrm{HNO}_{3}+\mathrm{O}_{2}
\end{aligned}
$$

The secondary ion chemistry described here requires two sequential reactions, the first to form $\mathrm{IO}^{-}$or $\mathrm{IO}_{3}{ }^{-}$, which then react with the analyte in a second step. Therefore, operation of the drift tube at lower pressures should reduce secondary ion chemistry by reducing the total number of collisions.

Laboratory calibrations show the decline of $\mathrm{I}^{-} \bullet \mathrm{HNO}_{3}$ and an increase of artificially detected $\mathrm{I}^{-} \bullet \mathrm{HNO}_{4}\left(\right.$ from $\left.\mathrm{IO}^{-} \bullet \mathrm{HNO}_{3}\right)$ as a function of ozone mixing ratio at various reaction pressures (Fig. 5). A fixed $\mathrm{HNO}_{3}$ mixing ratio was added during all experiments. Data for 40 and 93 mbar were measured with a standard I- CIMS (Veres et al, 2020). Our results show that a reduced operating pressure in Iodide CIMS reduces the potential of erroneous assignments of chemical species to peaks in the mass spectrum, although not completely eliminating this possibility.

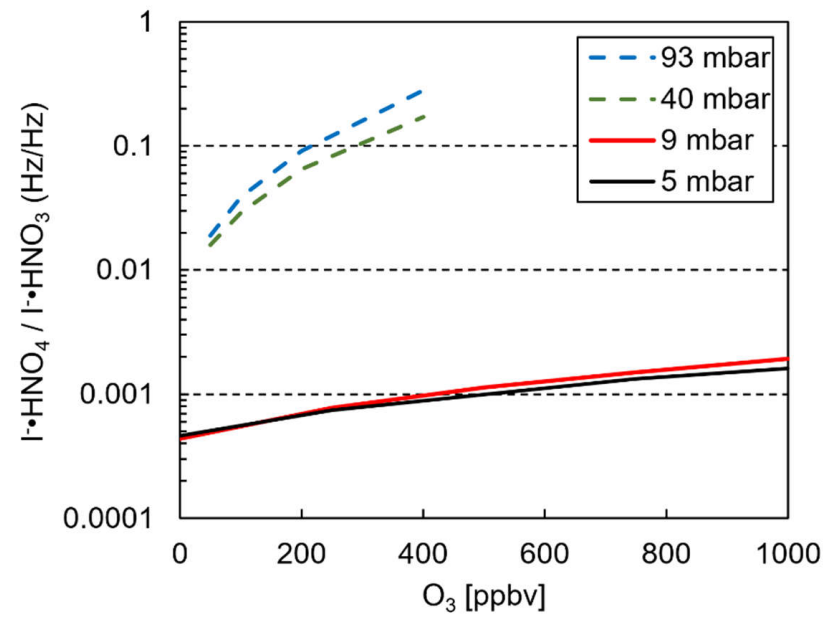

\begin{abstract}
Figure 5: Ratio of $\mathrm{I} \cdot \bullet \mathrm{HNO}_{4}$ and $\mathrm{I} \cdot \mathrm{HNO}_{3}$ as a function of ozone mixing ratio of the sample gas. Solid lines: Instrument described in this work operating at pressures indicated in the legend; Dashed lines: Data from a standard $I^{-}$-CIMS operated at pressures indicated in the legend (40 and 93 mbar).
\end{abstract}

\title{
4 Alternative reagent ion species
}

280 A variety of reagent ions of both polarities have been used to specifically detect different classes of compounds relevant in atmospheric chemistry. The VUV ion source is a versatile tool to produce different reagent ions of either polarity by using a suitable $\mathrm{CI}$ gas, with some limitations mainly arising from the photon energies from the source. Here we briefly describe experiments to demonstrate the capability of the VUV source to produce benzene $\left(\mathrm{C}_{6} \mathrm{H}_{6}{ }^{+}\right)$and ammonium $\left(\mathrm{NH}_{4}{ }^{+}\right)$cations. 


\subsection{Benzene ${ }^{+}$CIMS}

285 Benzene cations have been shown to be both sensitive and selective reagent ions for chemical ionization of select biogenic volatile organic compounds, including dimethyl sulfide (DMS, Kim et al., 2016), isoprene (Lavi et al., 2018) and monoterpenes (Lavi et al., 2018). Benzene $\left(\mathrm{C}_{6} \mathrm{H}_{6}\right)$ with an ionization potential of $9.24 \mathrm{eV}$ (NIST Chemistry Webbook, 2021) is directly ionized by the photons originating from the lamps, producing $\mathrm{C}_{6} \mathrm{H}_{6}{ }^{+}$primary ions. The most energetic photons emitted by the lamp have energies of $10.6 \mathrm{eV}$, significantly lower than the lowest appearance energy of any fragment from the benzene molecule $\left(\mathrm{C}_{6} \mathrm{H}_{5}{ }^{+}\right.$at $\left.12.90 \mathrm{eV}\right)$. Therefore, no fragment ion species are expected, nor observed. Benzene is added to the instrument by flowing 10 to $20 \mathrm{sccm}$ UHP nitrogen over a liquid reservoir (room temperature, ambient pressure), resulting in a benzene partial pressure of approx. 0.4 mbar in the source region, at an operating pressure of $3.8 \mathrm{mbar}$. Monoterpenes ( $\alpha$-pinene and limonene) and isoprene were detected at their respective adduct ions: $C_{6} H_{6}^{+} \bullet C_{10} H_{16}(\mathrm{~m} / \mathrm{z}=214.1716 \mathrm{Th})$ for monoterpenes and $C_{6} H_{6}^{+} \bullet C_{5} H_{8}(\mathrm{~m} / \mathrm{z}=146.1090 \mathrm{Th})$ for isoprene. No monoterpene fragment ion species were observed in the mass spectra. Sensitivities of $14 \mathrm{cps} / \mathrm{pptv}$ for $\alpha$-pinene, 27 $\mathrm{cps} / \mathrm{pptv}$ for limonene and $8.2 \mathrm{cps} / \mathrm{pptv}$ for isoprene were achieved, without significant humidity dependency, as shown in Figure $6 \mathrm{~b}$. The absence of fragmentation and humidity dependence observed here is a notable improvement over previous benzene CIMS instruments which report strong humidity dependence and a range of fragmentation products for various monoterpenes which complicates quantification with those instruments (Kim et al., 2016. Lavi et al., 2018).
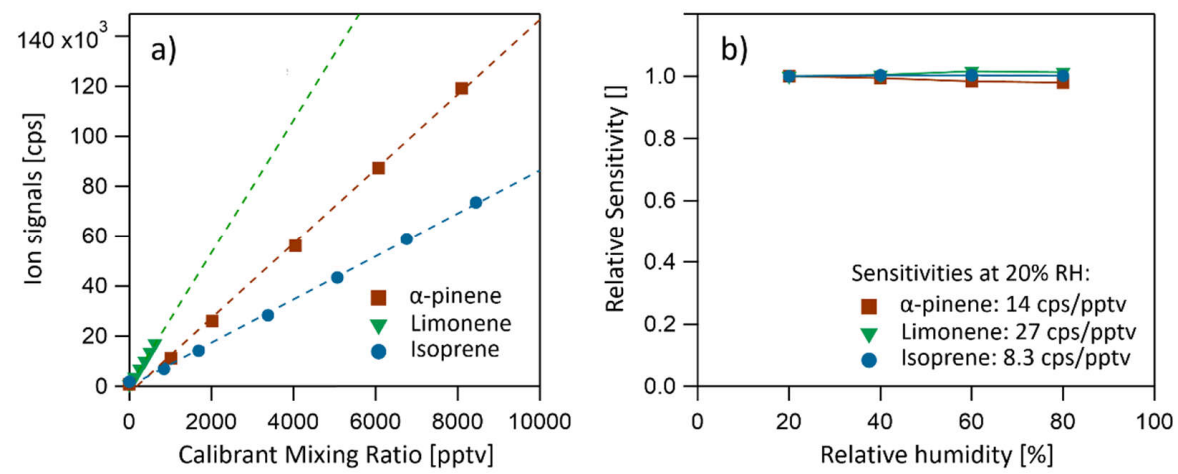

Figure 6: Calibrations in benzene mode; panel a) instrument response to selected biogenic calibrants (isoprene, $\mathrm{C}_{5} \mathrm{H}_{8} ; \alpha$-pinene, $\mathrm{C}_{10} \mathrm{H}_{16}$; limonene, $\left.\mathrm{C}_{10} \mathrm{H}_{16}\right)$; panel b) sample humidity dependency of the calibrants

\subsubsection{Propene-assisted ammonia ion generation}

Ammonium chemical ionization has been successfully used to ionize a wide range of oxygenated VOCs and is particularly suited for the detection of oxygenated species (Zaytsev et al, 2018). Ammonium primary ions were generated by flowing UHP nitrogen over a liquid reservoir filled with a $0.1 \mathrm{vol} \%$ ammonium hydroxide solution. Propene has an ionization potential of $9.73 \mathrm{eV}$ and a proton affinity of $752 \mathrm{~kJ} / \mathrm{mol}$ (NIST Chemistry Webbook, 2021). Ammonia has an ionization energy of $10.1 \mathrm{eV}$, lower than the higher-energetic photons emitted by the lamp. Therefore, a mixture of water vapor and ammonia in nitrogen can generate $\mathrm{NH}_{4}^{+} \bullet$ $\mathrm{H}_{2} \mathrm{O}$ reagent ions (Zaytsev et al, 2019). However, by increasing the volume mixing ratio of ammonia to a level where total primary ion currents are sufficiently high (approx. $>10^{7} \mathrm{cps}$ ), the formation of the less ideal reagent ion $\mathrm{NH}_{4}^{+} \bullet \mathrm{NH}_{3}$ becomes dominant. Since the PA of propene is lower than that of ammonia (proton affinity: $854 \mathrm{~kJ} / \mathrm{mol}$ ), proton transfer reactions can form ammonium reagent ions: 
Note that $\mathrm{H}_{3} \mathrm{O}^{+}$ions will not form, since the proton affinity of water $(691 \mathrm{~kJ} / \mathrm{mol}$, NIST Chemistry Webbook, 2021) is lower than the one of propene and the ratio of ammonia to water vapor will determine the ratio of $\mathrm{NH}_{4}^{+} \bullet \mathrm{H}_{2} \mathrm{O}$ to $\mathrm{NH}_{4}^{+} \bullet \mathrm{NH}_{3}$. Table 3 shows the individual primary ion intensities with and without the addition of propene as a dopant; For the same ammonia-water-nitrogen mixture, an overall 17-fold increase in primary ion intensities is observed. The reagent ion cluster distribution is controlled by ramping the drift voltage as shown in Figure 7. Being able to precisely control the ion energetics and subsequently the reagent ion cluster distribution is a key advantage of a drift tube compared to an IMR without ion guiding electronics.

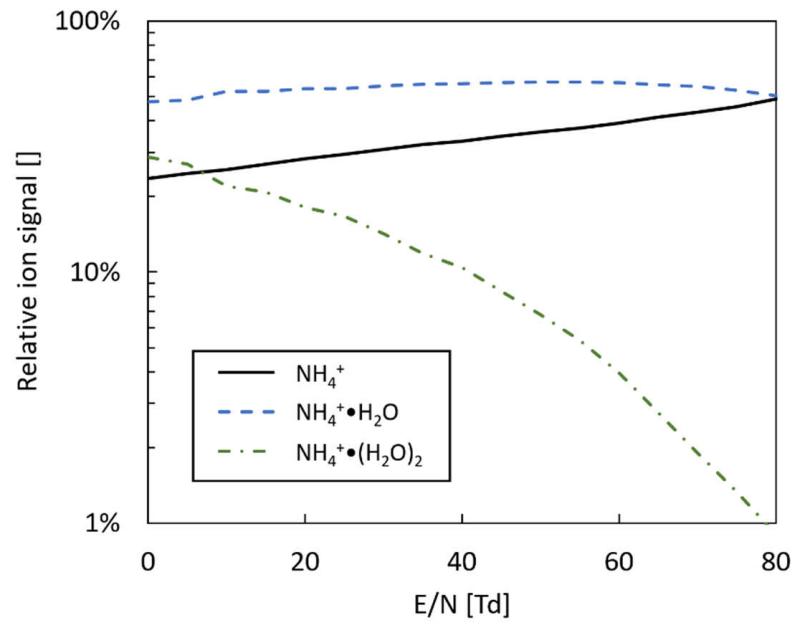

Figure 7: Reagent in cluster distribution in ammonia mode as a function of reduced electric field $(\mathrm{E} / \mathrm{N})$. Drift tube pressure: $2 \mathrm{mbar}$; drift tube temperature: $60^{\circ} \mathrm{C}$.

\begin{tabular}{lrrr} 
& \multicolumn{2}{c}{ Ion intensities $\left[10^{6} \mathrm{~Hz}\right]$} & \\
\cline { 2 - 3 } Ion formula & $\begin{array}{r}\text { No added } \\
\text { propene }\end{array}$ & $\begin{array}{r}1 \mathrm{sccm} \text { added } \\
\text { propene }\end{array}$ & $\begin{array}{r}\text { Enhancement } \\
\text { factor }\end{array}$ \\
\hline $\mathrm{NH}_{4}{ }^{+}$ & 0.14 & 5.61 & $40 \mathrm{x}$ \\
$\mathrm{NH}_{4} \cdot \mathrm{H}_{2} \mathrm{O}$ & 0.78 & 8.75 & $11 \mathrm{x}$ \\
$\mathrm{NH}_{4} \cdot \mathrm{NH}_{3}$ & 0.38 & 8.04 & $21 \mathrm{x}$ \\
\hline Total & 1.30 & 22.40 & $17 \mathrm{x}$ \\
\hline
\end{tabular}




\section{Summary}

We coupled a custom-designed VUV ion source to a commercially available Vocus Proton Transfer Reaction Mass Spectrometer. This ion source is designed to be compatible with the standard hollow-cathode glow discharge source included with the commercially available Vocus instrument. This allows for operation in both positive and negative ion VUV mode as well as easy conversion back to the original $\mathrm{H}_{3} \mathrm{O}^{+}$ion source. In this work, we demonstrate the flexibility of this VUV ion source through the generation of iodide ions, benzene cations, and ammonium cations. The reagent ion cluster distribution can be optimized for any given reagent ion species by adjusting the voltage across the Vocus drift tube. This capability provides improved control over target analytes compared to CIMS instruments with a standard IMR that does not support applying an electric field to the IMR.

345 The lower drift tube pressure ( 9 mbar) allows the instrument to operate over a wide range of ambient pressures (50 to $1000 \mathrm{mbar}$, ground level to an altitude of approx. $20 \mathrm{~km}$ ). These lower pressures reduce secondary ion chemistry present at elevated ozone levels, an effect that complicates quantification in standard iodide CIMS instrumentation. Additionally, the low operating pressures of the Vocus drift tube enhance the benefits of water addition by removing the sensitivity dependence on ambient humidity. Despite a significant reduction in operating pressure, we present sensitivities using iodide reagent ions that are comparable to other iodide CIMS instruments using both VUV ion sources as well as standard radioactive ion sources. An additional advantage of this ion source design, particularly for field deployment, is the 10 - 100-fold reduction in consumable gases required for iodide ion generation, using only $10-20 \mathrm{sccm}$ flow of $1000 \mathrm{ppm} \mathrm{CH}_{3} \mathrm{I}$ in nitrogen.

Coupling this reduced pressure, bipolar VUV ion source to a Vocus instrument is particularly well suited for conducting high altitude observations in the UT/LS and addresses the measurement challenges associated with low ambient pressures and a complex sample matrix. While designed specifically for the Vocus instrument, this ion source design is readily adaptable to most CIMS instruments. This work shows that low pressure operation of iodide ion CIMS using a VUV ion source provides significant advantages to more traditional modes of operation, without sacrificing the sensitivity and flexibility of this technique.

\section{Author contributions:}

360 AN, AR and PV initiated the project. MB, AN, AR and PV designed the experiment, MB and GN carried them out. MB and GN prepared the manuscript with contributions from all co-authors.

\section{Acknowledgements:}

M. Breitenlechner and G. Novak acknowledge support from an Earth's Radiation Budget grant, NOAA CPO Climate \& CI \#0301-07-001. This work was supported in part by the NOAA Cooperative Agreement with CIRES, NA17OAR4320101.

\section{References}

Bertram, T. H., Kimmel, J. R., Crisp, T. A., Ryder, O. S., Yatavelli, R. L. N., Thornton, J. A., Cubison, M. J., Gonin, M., and Worsnop, D. R.: A field-deployable, chemical ionization time-of-flight mass spectrometer, Atmos. Meas. Tech., 4, 1471-1479, https://doi.org/10.5194/amt-4-1471-2011, 2011. 
370 Caldwell, G. W., Masucci, J. A. and Ikonomou, M. G.: Negative ion chemical ionization mass spectrometry - binding of molecules to bromide and iodide anions, J. Org. Mass Spectrom, 24, 1, 8-14, https://doi.org/10.1002/oms.1210240103, 1989.

Crounse, J. D., McKinney, K. A., Kwan, A. J., and Wennberg, P. O.: Measurement of Gas-Phase Hydroperoxides by Chemical Ionization Mass Spectrometry, Anal. Chem., 78, 6726-6732, https://doi.org/10.1021/ac0604235, 2006.

de Gouw, J. and Warneke, C.: Measurements of Volatile Organic Compounds in the Earth's Atmosphere using Proton-TransferReaction Mass Spectrometry, Mass Spectrom. Rev., 26, 223-257, https://doi.org/10.1002/mas.20119, 2007.

De Gouw, J., Warneke, C., Karl, T., Eerdekens, G., van der Veen, C. and Fall, R.: Sensitivity and specificity of atmospheric trace 380 gas detection by proton-transfer-reaction mass spectrometry, Int. J. Mass Spectrom., 223-224, 365-382, https://doi.org/10.1016/S1387-3806(02)00926-0, 2003.

Dörich, R., Eger, P., Lelieveld, J., and Crowley, J. N.: Iodide-CIMS and m/z 62: The detection of $\mathrm{HNO}_{3}$ as $\mathrm{NO}_{3}{ }^{-}$in the presence of PAN, peracetic acid and $\mathrm{O}_{3}$, Atmos. Meas. Tech. Discuss. [preprint], https://doi.org/10.5194/amt-2021-57, in review, 2021.

Ehn, M., Thornton, J. A., Kleist, E., Sipilä, M., Junninen, H., Pullinen, I., Springer, M., Rubach, F., Tillmann, R., Lee, B., LopezHilfiker, F., Andres, S., Acir, I.-H., Rissanen, M., Jokinen, T., Schobesberger, S., Kangasluoma, J., Kontkanen, J., Nieminen, T., Kurtén, T., Nielsen, L. B., Jørgensen, S., Kjaergaard, H. G., Canagaratna, M., Maso, M. D., Berndt, T., Petäjä, T., Wahner, A., Kerminen, V.-M., Kulmala, M., Worsnop, D. R., Wildt, J., and Mentel, T. F.: A large source of low-volatility secondary organic 390 aerosol, Nature, 506, 476-479, https://doi.org/10.1038/nature13032, 2014.

Eisele, F. and Tanner, D.: Measurement of the gas phase concentration of $\mathrm{H}_{2} \mathrm{SO}_{4}$ and methane sulfonic acid and estimates of $\mathrm{H}_{2} \mathrm{SO}_{4}$ production and loss in the atmosphere, J. Geophys. Res., 98, D5, 9001-9010, doi:10.1029/93JD00031, 1993.

395 Hansel, A., Jordan, A., Holzinger, R., Prazeller, P., Vogel, W. and Lindinger, W.: Proton transfer reaction mass spectrometry: online trace gas analysis at the ppb level, In. J. Mass Spectrom. and Ion Proc., 149-150, 609-619, https://doi.org/10.1016/01681176(95)04294-U, 1995.

Hiraoka, K.; Mizuse, S. and Yamabe, S., Solvation of Halide Ions with $\mathrm{H}_{2} \mathrm{O}$ and $\mathrm{CH}_{3} \mathrm{CN}$ in the Gas Phase, J. Phys. Chem., 1988, 92, 13, 3943, https://doi.org/10.1021/j100324a051, 1988.

Huey, L. G.: Measurement of trace atmospheric species by chemical ionization mass spectrometry: Speciation of reactive nitrogen and future directions, Mass Spectrom. Rev., 26, 166-184, https://doi.org/10.1002/mas.20118, 2007.

Ji, Y., Huey, L. G., Tanner, D. J., Lee, Y. R., Veres, P. R., Neuman, J. A., Wang, Y., and Wang, X.: A vacuum ultraviolet ion source (VUV-IS) for iodide-chemical ionization mass spectrometry: a substitute for radioactive ion sources, Atmos. Meas. Tech., 13, 3683-3696, https://doi.org/10.5194/amt-13-3683-2020, 2020. 
Jokinen, T., Sipilä, M., Junninen, H., Ehn, M., Lönn, G., Hakala, J., Petäjä, T., Mauldin III, R. L., Kulmala, M., and Worsnop, D.

410 R.: Atmospheric sulphuric acid and neutral cluster measurements using CI-APi-TOF, Atmos. Chem. Phys., 12, 4117-4125, https://doi.org/10.5194/acp-12-4117-2012, 2012.

Kilpatrick, D. W.: An experimental mass-mobility relation for ions in air at atmospheric pressure. Proc. Annu. Conf. Mass. Spectrosc. 19, 320-325, 1971.

415

Kim, M. J., Zoerb, M. C., Campbell, N. R., Zimmermann, K. J., Blomquist, B. W., Huebert, B. J., and Bertram, T. H.: Revisiting benzene cluster cations for the chemical ionization of dimethyl sulfide and select volatile organic compounds, Atmos. Meas. Tech., 9, 1473-1484, https://doi.org/10.5194/amt-9-1473-2016, 2016.

420 Krechmer, J., Lopez-Hilfiker, F., Koss, A., Hutterli, M., Stoermer, C., Deming, B., Kimmel, J.,Warneke, C., Holzinger, R., Jayne, J., Worsnop, D., Fuhrer, K., Gonin, M. and de Gouw, J: Evaluation of a New Reagent-Ion Source and Focusing Ion-Molecule Reactor for Use in Proton-Transfer-Reaction Mass Spectrometry, Anal. Chem., 90-20, 12011-12018, https://doi.org/10.1021/acs.analchem.8b02641, 2018. spectrometry to select biogenic terpenes, Atmos. Meas. Tech., 11, 3251-3262, https://doi.org/10.5194/amt-11-3251-2018, 2018.

Lee, B. H., Lopez-Hilfiker, F. D., Mohr, C., Kurtén, T., Worsnop, D. R. and Thornton, J. A.: An Iodide-Adduct High-Resolution Time-of-Flight Chemical-Ionization Mass Spectrometer: Application to Atmospheric Inorganic and Organic Compounds, Environ.

430 Sci. Technol. 48, 11, 6309-6317, https://doi.org/10.1021/es500362a, 2014.

Lee, B. H., Lopez-Hilfiker, F. D., Veres, P. R., McDuffie, E. E., Fibiger, D. L., Sparks, T. L., Ebben, C. J., Green, J. R., Schroder, J. C., Campuzano-Jost, P., Iyer, S., D'Ambro, E. L., Schobesberger, S., Brown, S. S., Wooldridge, P. J., Cohen, R. C., Fiddler, M. N., Bililign, S., Jimenez, J. L., Kurten, T., Weinheimer, A. J., Jaegle, L. and Thornton, J. A.: Flight deployment of a high-resolution

435 time-of-flight chemical ionization mass spectrometer: Observations of reactive halogen and nitrogen oxide species, J. G. R. Atmospheres, 123, 7670-7686. https://doi.org/10.1029/2017JD028082, 2018.

Leibrock, E. and Huey, L. G.: Ion chemistry for the detection of isoprene and other volatile organic compounds in ambient air, Geophys. Res. Lett., 27, 1719-1722, https://doi.org/10.1029/1999GL010804, 2000.

Liao, J., Huey, L. G., Liu, Z., Tanner, D. J., Cantrell, C. A., Orlando, J. J., Flocke, F. M., Shepson, P. B., Weinheimer, A. J., Hall, S. R., Ullmann, K., Beine, H. J., Wang, Y., Ingall, E. D., Stephens, C. R., Hornbrook, R. S., Apel, E. C., Riemer, D., Fried, A., Mauldin III, R. L., Smith, J. N., Staebler, R. M., Neuman, J. A. and Nowak, J. B.: High levels of molecular chlorine in the Arctic atmosphere, Nature Geoscience, 7, 91-94, https://doi.org/10.1038/ngeo2046, 2014.

Müller, M., Piel, F., Gutmann, R., Sulzer, Ph., Hartungen, E. and Wisthaler, A.: A novel method for producing $\mathrm{NH}_{4}^{+}$reagent ions $^{-}$ in the hollow cathode glow discharge ion source of PTR-MS instruments, Int. Jour. Mass Spectrom., 447:116254, 1-4, https://doi.org/10.1016/j.ijms.2019.116254, 2020. 
450 Neuman, J. A., Nowak, J. B., Huey, L. G., Burkholder, J. B., Dibb, J. E., Holloway, J. S., Liao, J., Peischl, J., Roberts, J. M., Ryerson, T. B., Scheuer, E., Stark, H., Stickel, R. E., Tanner, D. J. and Weinheimer, A.: Bromine measurements in ozone depleted air over the Arctic Ocean, Atmos. Chem. Phys., 10, 6503-6514, https://doi.org/10.5194/acp-10-6503-2010, 2010.

NIST Chemistry Webbook, https://webbook.nist.gov/, last access: July $12^{\text {th }}, 2021$.

Roberts, J. M., Veres, P., Warneke, C., Neuman, J. A., Washenfelder, R. A., Brown, S. S., Baasandorj, M., Burkholder, J. B., Burling, I. R., Johnson, T. J., Yokelson, R. J., and de Gouw, J.: Measurement of HONO, HNCO, and other inorganic acids by negative-ion proton-transfer chemical-ionization mass spectrometry (NI-PT-CIMS): application to biomass burning emissions, Atmos. Meas. Tech., 3, 981-990, https://doi.org/10.5194/amt-3-981-2010, 2010.

460

Pollack, I. B., Lerner, B. M. and Ryerson, T. B.: Evaluation of ultraviolet light-emitting diodes for detection of atmospheric $\mathrm{NO}_{2}$ by photolysis - chemiluminescence, J. Atmos. Chem. 65, 111-125, https://doi.org/10.1007/s10874-011-9184-3, 2010

Slusher, D. L., Huey, L. G., Tanner, D. J., Flocke, F. M. and Roberts, J. M.: A thermal dissociation-chemical ionization mass spectrometry (TD-CIMS) technique for the simultaneous measurement of peroxyacyl nitrates and dinitrogen pentoxide, J. Geophys. R. Atmos., 109, D19, https://doi.org/10.1029/2004JD004670, 2004.

Simon, M., Heinritzi, M., Herzog, S., Leiminger, M., Bianchi, F., Praplan, A., Dommen, J., Curtius, J., and Kürten, A.: Detection of dimethylamine in the low pptv range using nitrate chemical ionization atmospheric pressure interface time-of-flight (CI-APiTOF) mass spectrometry, Atmos. Meas. Tech., 9, 2135-2145, https://doi.org/10.5194/amt-9-2135-2016, 2016.

470

Thaler, R. D., Mielke, L. H. and Osthoff, H. D.: Quantification of Nitryl Chloride at Part Per Trillion Mixing Ratios by Thermal Dissociation Cavity Ring-Down Spectroscopy, Anal. Chem 83, 7, 2761-2766, https://doi.org/10.1021/ac200055z, 2011.

Tofwerk AG Vocus product website, https://www.tofwerk.com/products/vocus, last access: 4 August 2021.

Veres, P., Roberts, J. M., Warneke, C., Welsh-Bon, D., Zahniser, M., Herndon, S., Fall, R. and de Gouw, J.: Development of negative-ion proton-transfer chemical-ionization mass spectrometry (NI-PT-CIMS) for the measurement of gas-phase organic acids in the atmosphere, Int. J. Mass Spectrom. 274, 1-3, 48-55, https://doi.org/10.1016/j.ijms.2008.04.032, 2008.

480 Veres, P. R., Neuman, J. A., Bertram, T. H., Assaf, E., Wolfe, G. M., Williamson, C. J., Weinzierl, B., Tilmes, S., Thompson, C. R., Thames, A. B., Schroder, J. C., Saiz-Lopez, A., Rollins, A. W., Roberts, J. M., Price, D., Peischl, J., Nault, B. A., Møller, K. H., Miller, D. O., Meinardi, S., Li, Q., Lamarque, J-F. Kupc, A., Kjaergaard, H. G., Kinnison, D., Jimenez, J. L., Jernigan, C. M., Hornbrook, R. S., Hills, A., Dollner, M., Day, D. A., Cuevas, C. A., Campuzano-Jost, P., Burkholder, J., Bui, T. P., Brune, W. H., Brown, S. S., Brock, C. A., Bourgeois, I., Blake, D. R., Apel, E. C. and Ryerson, T.B.: Global airborne sampling reveals a 485 previously unobserved dimethyl sulfide oxidation mechanism in the marine atmosphere, Proc. Nat. Academy Sci., 117 (9), $4505-$ 4510, https://doi.org/10.1073/pnas.1919344117, 2020. 
https://doi.org/10.5194/amt-2021-330

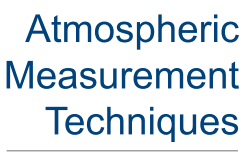

Preprint. Discussion started: 14 October 2021

(C) Author(s) 2021. CC BY 4.0 License.

Warneke, C., van der Veen, C., Luxembourg, S., de Gouw, J. A. and Kok, A.: Measurements of benzene and toluene in ambient air using proton-transfer-reaction mass spectrometry: calibration, humidity dependence, and field intercomparison, Int. J. Mass

490 Spectrom., 207, 3, 167-182, https://doi.org/10.1016/S1387-3806(01)00366-9, 2000.

Zaytsev, A., Breitenlechner, M., Koss, A. R., Lim, C. Y., Rowe, J. C., Kroll, J. H. and Keutsch, F. N.: Using collision-induced dissociation to constrain sensitivity of ammonia chemical ionization mass spectrometry $\left(\mathrm{NH}_{4}{ }^{+}\right.$CIMS) to oxygenated volatile organic compounds, Atmos. Meas. Tech., 12, 1861-1870, https://doi.org/10.5194/amt-12-1861-2019, 2019.

495

Zhang, W. and Zhang, H.: Secondary Ion Chemistry Mediated by Ozone and Acidic Organic Molecules in Iodide-Adduct Chemical Ionization Mass Spectrometry, Anal. Chem., 93, 24, 8595-8602, https://doi.org/10.1021/acs.analchem.1c01486, 2021. 